\title{
QUALIDADE MICROBIOLÓGICA DA ÁGUA PARA CONSUMO
}

\section{HUMANO EM ASSENTAMENTOS DO MUNICÍPIO DE TEODORO}

\author{
SAMPAIO - SP
}

\section{André Turin Santana ${ }^{1}$}

\section{Renata Medici Frayne Cuba ${ }^{2}$}

RESUMO: A água é um recurso natural essencial à vida, e sua qualidade é fundamental para a manutenção da saúde. Assim o objetivo deste trabalho foi avaliar a qualidade microbiológica da água utilizada para consumo humano em diversos assentamentos localizados na cidade de Teodoro Sampaio - SP. Para isso, foram coletadas amostras em 43 poços e seus respectivos reservatórios em 43 lotes de 6 assentamentos rurais, para ensaios de coliformes totais e E. coli,. Os resultados mostraram que $72 \%$ dos poços e 86 \% dos reservatórios estão fora dos padrões de potabilidade estabelecidos pelo Ministério da Saúde. Conclui-se que $86 \%$ das famílias que ocupam os lotes nos assentamentos estudados, consomem água fora dos padrões de potabilidade.

Palavras - chave: Água Potável. Água subterrânea. Microbiologia. Assentamento rural. Teodoro Sampaio.

\section{INTRODUÇÃO}

\footnotetext{
${ }^{1}$ Mestrando em Meio Ambiente e Desenvolvimento Regional, Universidade do Oeste Paulista - UNOESTE. andretquimico@yahoo.com.br

${ }^{2}$ Doutora em Hidráulica e Saneamento pela Escola de Engenharia de São Carlos - USP. renatamedici@unoeste.br
} 
As atividades antrópicas e o desenvolvimento têm determinado alterações significativas no meio ambiente, influenciando na qualidade da água e sua disponibilidade. Em função da escassez de água e da deterioração dos mananciais, o acesso à água de boa qualidade é uma crescente preocupação da humanidade.

A água é um recurso natural essencial à vida, e sua qualidade é fundamental para a manutenção da saúde, sendo assim, a água destinada ao consumo humano deve atender a padrões de qualidade que são recomendados pelo Ministério da Saúde por meio da portaria no 2.914 de 2011, que define valores máximos permissíveis para as características, organolépticas, físico-químicas e bacteriológicas (BRASIL, 2011; BRASIL, 2006).

Quando contaminada a água pode veicular um grande numero de doenças. Dentre estas, as mais comuns são diarreias e disenterias, como por exemplo, febre tifóide, cólera, salmonelose, shigelose e outras gastroenterites, poliomielite, hepatite $A$, verminoses, amebíase e giardíase (MATOS, 2001). De acordo com Santoni (2010), existem diversos estudos que relacionam o consumo de água contaminada com altos índices de internações hospitalares, proliferação de doenças e elevadas taxas de mortalidade, especialmente a infantil. Sendo assim, o acesso a água de boa qualidade pode garantir uma melhora na saúde da população.

Segundo pesquisa do Instituto Brasileiro de Geografia e Estatística - IBGE (2010) somente $78,6 \%$ da população brasileira tem acesso de boa qualidade. Ainda com relação aos resultados da pesquisa, a falta de acesso à água tratada, junto com aos demais componentes do saneamento básico como o esgotamento sanitário adequado, a disposição de resíduos sólidos e o manejo de águas pluviais, podem comprometer a saúde, bem-estar e a qualidade de vida da sociedade, contribuindo também com a degradação ambiental.

De acordo com Brasil (2011) e Casali (2008), a água utilizada para abastecimento público, ou privado, deve ser potável, assim, possuir características e substâncias que não ofereçam riscos para os seres vivos que a consomem, como animais e homens. Desta forma, manter a água potável e constantemente disponível ao homem é uma das obrigações dos órgãos governamentais. 
No Brasil considerando as áreas urbanas e rurais $81,1 \%$ dos municípios possuem sistema de distribuição e tratamento de água, sendo as regiões sul e sudeste com maior numero de municípios. Já na região norte do país $40 \%$ dos municípios não possuem sistemas de tratamento de água. Com relação ao controle de qualidade da água, no país apenas 70 \% dos municípios contam com controle bacteriológico da água (INSTITUTO TRATA BRASIL, 2013, BRASIL, 2006).

Nas áreas rurais apenas $9 \%$ da população tem acesso à rede de distribuição de água tratada, os demais precisam recorrer a métodos alternativos para obtenção de água, como a captação de água subterrânea através de poços. Devido à água subterrânea possuir melhor qualidade do que as águas superficiais, consequência da percolação através do solo, é dispensada quase em sua totalidade as etapas inerentes a sua potabilização, sendo o tratamento restringido apenas a filtração, desinfecção e eventual correção no pH ( AGENCIA NACIONAL DE ÁGUAS - ANA, 2005; BRASIL,2006).

No Brasil, a desinfecção da água é realizada através da cloração, representando um beneficio indiscutível à saúde humana, uma vez que o cloro, em qualquer de seus compostos, é capaz de destruir e tornar inativos os organismos causadores de enfermidades. Sua aplicação é simples, exigindo equipamentos de baixo custo; e é relativamente seguro ao homem nas dosagens habitualmente adotadas $\left(2,0 \mathrm{mg} \cdot \mathrm{L}^{-1}\right)$ para a desinfecção da água ( SANTOS, GOUVEIA; 2011).

Casali (2008) ressalta que no meio rural é quase inexistente o tratamento da água, e que além dos fatores antrópicos, as condições de captação e armazenamento precários são responsáveis pela contaminação da água e consequentemente a veiculação de doenças.

Em assentamentos da reforma agraria o cenário é o mesmo, segundo o Movimento dos Trabalhadores Rurais Sem Terra - MST (2010) 55 \% dos assentamentos rurais no Brasil não tem água potável. No município de Teodoro Sampaio, de acordo com o Plano de Desenvolvimento Rural para os anos de 2010 - 2013, na zona rural a água é proveniente de poços e não recebe tratamento, mesmo nos assentamentos da reforma agraria que são de responsabilidade do poder publico (TEODRORO SAMPAIO, 2010).

As situações apresentadas reforçam a necessidade em se fazer uma avaliação da qualidade das águas subterrâneas utilizadas nos assentamentos. Sendo assim, 0 presente trabalho objetivou avaliar a qualidade microbiológica da água utilizada para 
consumo humano em diversos assentamentos localizados na cidade de Teodoro Sampaio $-\mathrm{SP}$.

\section{MATERIAL E MÉTODOS}

\section{$2.1 \quad$ Local de Estudo}

O estudo foi realizado nos assentamentos da reforma agrária: Santa Zélia, Santa Terezinha da Alcídia, Alcídia da Gata, Santo Expedito, Vô Tonico e Laudenor de Souza, situados na cidade de Teodoro Sampaio região da UGRHI - 22 Pontal do Paranapanema extremo oeste do estado de São Paulo, estes possuem famílias de origens variadas que foram assentadas a partir do ano de 1997, tendo como principal diferença os manejos agropecuários, área ocupada entre outras (VALENCIANO, 2001).

Estes assentamentos foram selecionados devido existirem na região a mais de 10 anos e por possuírem diversidade nos manejos agrícolas (LEAL,2003). Também na caracterização preliminar do estudo verificou-se a inexistência de saneamento básico e monitoramento da qualidade da água para consumo humano.

\subsection{Localização dos Pontos e Amostragem}

Inicialmente foi realizada a identificação dos poços existentes nos assentamentos com as iniciais do assentamento e o respectivo numero do lote onde ele se encontra, quando foi determinado o posicionamento dos mesmos, localizando suas coordenadas em "Universal Transversa de Mercator", UTM utilizando-se "Global Position Siste", GPS de navegação Garmin modelo Etrex. As amostras dos reservatórios de água nos assentamentos foram identificadas com o numero do respectivo lote.

As amostras foram coletadas em frasco de vidro com capacidade volumétrica de $250 \mathrm{~mL}$ previamente esterilizados a $121^{\circ} \mathrm{C}$ por 15 minutos, com a tampa protegida com papel alumínio. Durante as coletas foram tomados cuidados com a sanitização das torneiras com etanol $77^{\circ} \mathrm{GL}$, escoamento da água parada na tubulação e com a preservação, armazenamento e transporte das amostras de água, a fim de não provocar alterações nas características das mesmas. Cada frasco foi devidamente identificado, e posteriormente acondicionado em caixa térmica com gelo (APHA, 2005). 
Estes poços e reservatórios foram amostrados em quatro etapas (Março/2013, Abril/2013, Maio/2013 e Junho/20013), com auxilio de alunos de projetos de iniciação cientifica.

\subsection{Ensaio Microbiológico}

Foram quantificados os coliformes totais e coliformes fecais especificamente a Escherichia coli.

A quantificação dos coliformes foi realizada em duplicata, por meio da técnica de filtração em membrana, utilizando como meio de cultura o Chromocult Coliforme Agar® da Merck (cat. 1.10426) com substrato cromogênico. Esse meio foi preparado a partir da dissolução de $26,5 \mathrm{~g}$ em 1 litro de água destilada, utilizando-se banho-maria. Em seguida volumes de $4 \mathrm{~mL}$ do meio foram distribuídos em Placas de Petri esterilizadas, e, após a solidificação do meio, as placas foram mantidas sob refrigeração até o momento de uso.

O Chromocult $\circledast$ é uma combinação de dois substratos cromogênicos (Salmon-GAL e X-glicuronídeo - substratos enzimáticos sintéticos) que possibilita a deteç̧ão de coliformes totais e fecais (E. coll), em uma mesma placa que é diferenciada pela cor, conforme apresentado na Figura 1.

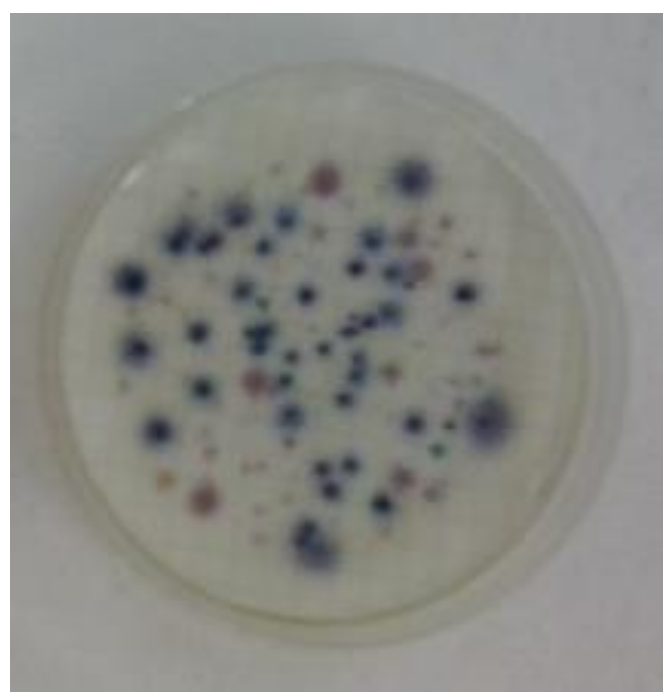

FIGURA 1. Placa de Petri com colônias coliformes totais e E. coli Fonte: Próprio autor. 
O procedimento para quantificação dos microrganismos consistiu na filtração de $100 \mathrm{~mL}$ de amostra, ou de sua diluição, através de membrana esterilizada e com porosidade de retenção de $0,45 \mu \mathrm{m}$.

Após a filtração, a membrana foi colocada em placa de Petri sobre o meio de cultura e incubada em estufa de cultura marca Químis à temperatura de $36 \pm 1^{\circ} \mathrm{C}$ por $24 \pm$ 1h. Após este período foi efetuada a contagem das unidades formadoras de colônias (UFC), baseada na coloração para identificação dos microrganismos (colônias azul escuro a violeta: E. coli; vermelho a salmão: coliformes totais) e os resultados foram expressos em UFC. $100 \mathrm{~mL}^{-1}$.

A água de diluição foi tratada com duas soluções estoques. A solução estoque "A" (fosfato monopotássico, $34 \mathrm{~g} \cdot \mathrm{L}^{-1}$ ) cujo $\mathrm{pH}$ foi ajustado para 7,2 com solução de hidróxido de sódio $1 \mathrm{~N}$, e a solução estoque "B" (cloreto de magnésio hexa hidratado, 81,1 g. $L^{-1}$ ). A quantidade utilizada era de $1,25 \mathrm{~mL}$ da solução estoque $A$ e $5,0 \mathrm{~mL}$ de solução estoque $B$ por $1000 \mathrm{~mL}$ de água purificada. Antes do uso, a água de diluição era esterilizada em autoclave a $121^{\circ} \mathrm{C}$ por 15 minutos (APHA, 2005).

Os ensaios foram realizados no Laboratório de Análise de Água Microbiológica da UNOESTE, e a metodologia analítica utilizada teve como base as metodologias descritas pela APHA, (2005).

\section{RESUltAdOS E discussão}

\subsection{Amostragem}

Na Figura 2 é apresenta a localização geográfica dos 43 poços amostrados. 


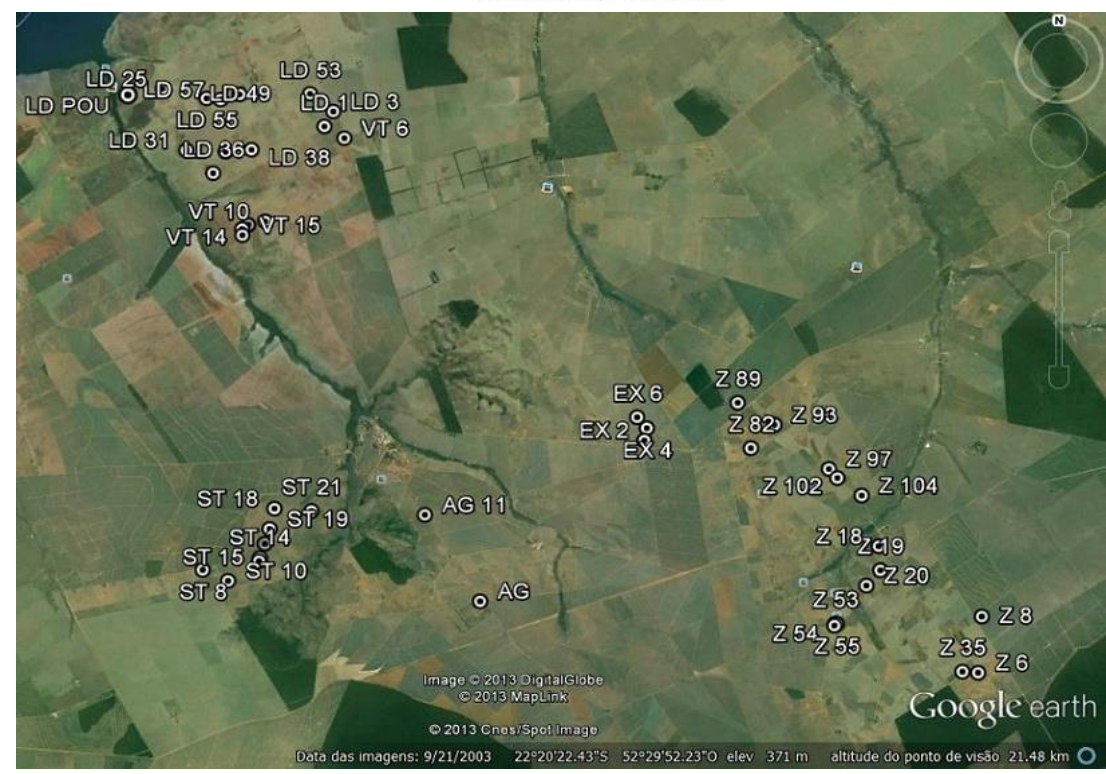

FIGURA 2. Imagem de satélite com a localização dos poços amostrados.

Fonte: Google Earth.

Foram identificados, e amostrados, 37 poços tubulares com uma variação na faixa de 40 á 130 metros de profundidade e 6 poços simples com uma variação na faixa de 14 á 37 metros de profundidade, em 43 lotes distribuídos nos 6 assentamentos. Também foram amostrados 43 reservatórios de água, abastecidos pelos poços.

\subsection{Qualidade microbiológica das águas}

A Tabela 1 apresenta os resultados microbiológicos dos poços.

TABELA 1. Coliformes Totais e Escherichia coli em águas dos poços nos lotes dos assentamentos.

\begin{tabular}{ccc} 
Poço & $\begin{array}{c}\text { Coli. Totais } \\
\text { UFC.100 } \mathrm{mL}^{-1} \mathrm{H}_{2} \mathrm{O}^{2}\end{array}$ & $\begin{array}{c}\text { Escherichia coli } \\
\text { UFC. } 100 \mathrm{~mL}^{-1} \mathrm{H}_{2} \mathrm{O}^{2}\end{array}$ \\
\hline Z 06 & Assentamento Santa Zélia & \\
Z 08 & 150 & Ausente \\
Z 18 & 7 & Ausente \\
Z 19 & 6 & Ausente \\
Z 20 & 320 & Ausente \\
Z 35 & Ausente & Ausente \\
Z 40 & 13 & 6 \\
Z 53 & 63 & 10 \\
Z 54 & 470 & Ausente \\
Z 82 & Ausente & Ausente \\
Z 97 & Ausente & Ausente \\
Z 104 & 13 & Ausente \\
& A7 & Ausente \\
\hline
\end{tabular}


ISSN 1980-0827

Fórum Ambiental

da Alta Paulista

Volume 9, Número 11, 2013

Saúde, Saneamento e

Meio Ambiente

\begin{tabular}{|c|c|c|}
\hline AG 05 & 50 & Ausente \\
\hline \multicolumn{3}{|c|}{ Assentamento Santa Terezinha da Alcídia } \\
\hline ST 6 & 10 & Ausente \\
\hline ST 8 & 60 & 6 \\
\hline ST 10 & 20 & Ausente \\
\hline ST 14 & 73 & 30 \\
\hline ST 15 & 20 & Ausente \\
\hline ST 17 & 266 & 20 \\
\hline ST 18 & 63 & 20 \\
\hline ST 19 & 40 & Ausente \\
\hline ST 21 & Ausente & Ausente \\
\hline \multicolumn{3}{|c|}{ Assentamento Santo Expedito } \\
\hline EX 2 & Ausente & Ausente \\
\hline EX 4 & 20 & Ausente \\
\hline EX 6 & 30 & 10 \\
\hline \multicolumn{3}{|c|}{ Assentamento Vô Tonico } \\
\hline VT 6 & Ausente & Ausente \\
\hline VT 10 & 30 & Ausente \\
\hline VT 12 & 50 & Ausente \\
\hline VT 14 & 400 & Ausente \\
\hline VT 15 & 80 & 15 \\
\hline \multicolumn{3}{|c|}{ Assentamento Laudenor de Souza } \\
\hline LD 1 & Ausente & Ausente \\
\hline LD 3 & Ausente & Ausente \\
\hline LD 8 & Ausente & Ausente \\
\hline LD 25 & Ausente & Ausente \\
\hline LD 29 & 100 & Ausente \\
\hline LD 31 & 10 & Ausente \\
\hline LD 36 & 80 & Ausente \\
\hline LD 38 & 100 & 80 \\
\hline LD 49 & 140 & 120 \\
\hline LD 53 & Ausente & Ausente \\
\hline LD 55 & Ausente & Ausente \\
\hline LD 57 & 50 & Ausente \\
\hline LD POU & 5 & Ausente \\
\hline
\end{tabular}

${ }^{1}$ Padrão de consumo humano: Ausência de Coliformes totais e Escherichia coli- ${ }^{2}$ Resultados médios das Unidades formadoras de colônias por $100 \mathrm{~mL}$ de água.

Segundo a Tabela 1, a presença de coliformes totais foi detectada nas águas de 31 (72\%), amostras de poços, sendo que 10 (23,3\%) continham bactérias Escherichia coli, apresentando-se fora dos padrões estabelecidos pela Portaria ํㅡ 2.914 de 2011 do Ministério da Saúde, ausência em $100 \mathrm{~mL}$ de amostra de bactérias do grupo coliformes (Brasil, 2011). Conforme esta portaria, em amostras individuais procedentes de sistemas alternativos de abastecimento (poços, fontes, nascentes e outras formas de abastecimento sem distribuição canalizada e tratada), somente será tolerada a presença de coliformes totais na ausência de E. coli. No entanto, ressalta que se deve investigar a origem da fonte de contaminação e tomar as providências imediatas de caráter corretivo e preventivo. Também é imprescindível que sejam tomadas medidas para a desinfecção destes poços e o tratamento da água. 
Ressalva-se que a água, mesmo que cristalina e aparentemente própria para o consumo, pode estar contaminada por microrganismos patogênicos, causando diarreias, vômitos e outras enterites, sendo que, as principais formas de contaminação microbiológica da água subterrânea são: à presença de fossas sépticas fora dos padrões exigíveis, e a má construção dos poços que devem possuir selo sanitário e laje de concreto para evitar infiltrações (BRASIL, 2006).

A água proveniente destes poços abastecem os reservatórios de água, amostrados para o ensaio de coliformes totais e E. coli, conforme apresentado na Tabela 2.

TABELA 2. Coliformes Totais e Escherichia coli em águas dos reservatórios nos lotes dos assentamentos.

\begin{tabular}{|c|c|c|}
\hline Lote & $\begin{array}{c}\text { Coli. Totais } \\
\text { UFC. } 100 \mathrm{~mL}^{-1} \mathrm{H}_{2} \mathrm{O}^{2}\end{array}$ & $\begin{array}{l}\text { Escherichia coli } \\
\text { UFC. } 100 \mathrm{~mL}^{-1} \mathrm{H}_{2} \mathrm{O}^{2}\end{array}$ \\
\hline \multicolumn{3}{|c|}{ Assentamento Santa Zélia } \\
\hline 06 & 600 & 40 \\
\hline 08 & 528 & Ausente \\
\hline 18 & 6 & Ausente \\
\hline 19 & 500 & Ausente \\
\hline 20 & Ausente & Ausente \\
\hline 35 & 13 & 23 \\
\hline 40 & 249 & 33 \\
\hline 53 & 426 & Ausente \\
\hline 54 & 102 & Ausente \\
\hline 55 & 700 & Ausente \\
\hline 82 & Ausente & Ausente \\
\hline 89 & 13 & 7 \\
\hline 97 & 23 & Ausente \\
\hline 102 & 1100 & Ausente \\
\hline \multicolumn{3}{|c|}{ Assentamento Alcídia da Gata } \\
\hline 05 & 50 & 30 \\
\hline 11 & 66 & Ausente \\
\hline \multicolumn{3}{|c|}{ Assentamento Santa Terezinha da Alcídia } \\
\hline 06 & 10 & Ausente \\
\hline 08 & 160 & 20 \\
\hline 10 & 950 & Ausente \\
\hline 14 & 6 & Ausente \\
\hline 15 & 303 & 43 \\
\hline 17 & 140 & 90 \\
\hline 18 & 17 & 13 \\
\hline 19 & 580 & Ausente \\
\hline 21 & 100 & Ausente \\
\hline
\end{tabular}

Assentamento Santo Expedito 


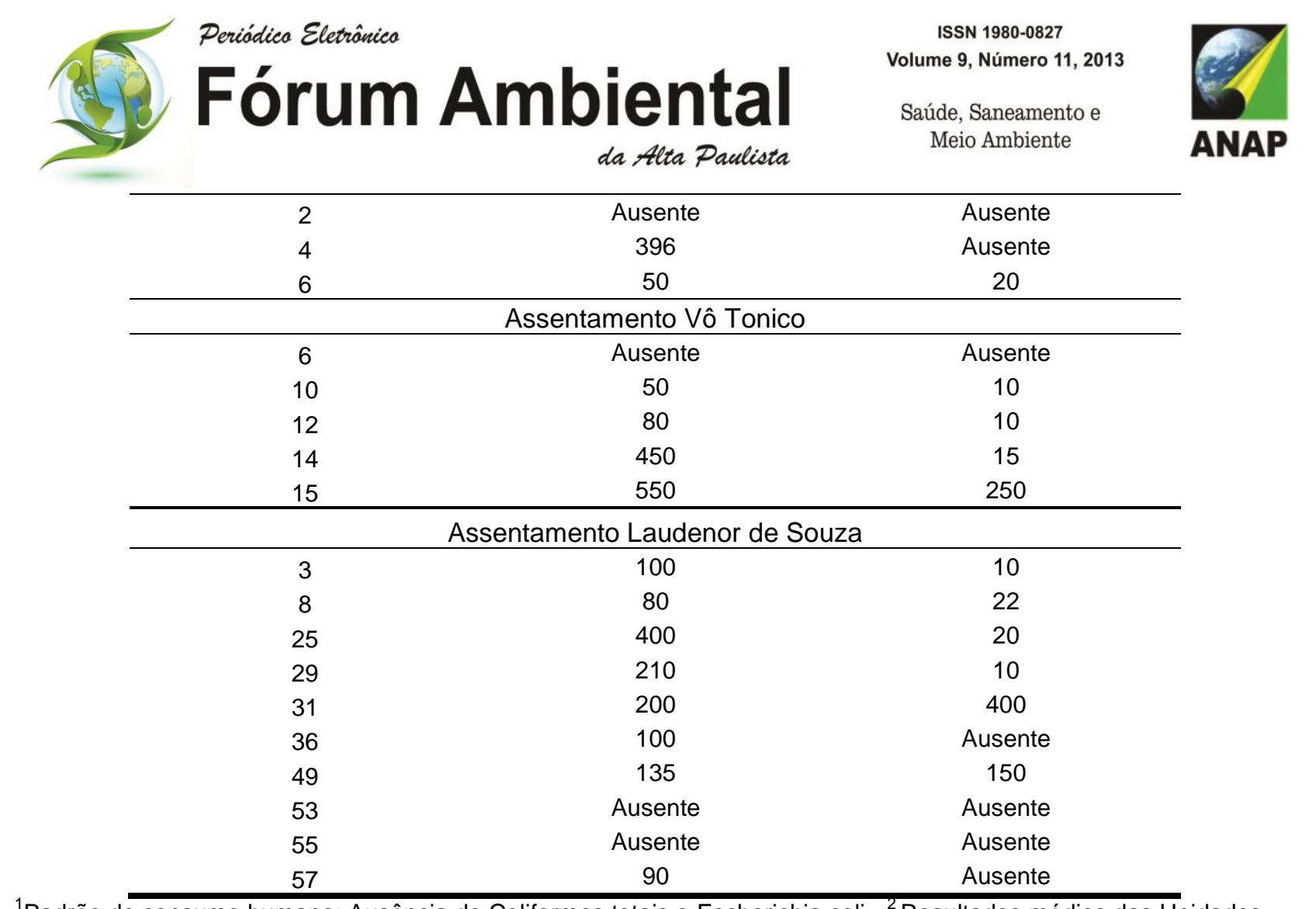

${ }^{1}$ Padrão de consumo humano: Ausência de Coliformes totais e Escherichia coli- ${ }^{2}$ Resultados médios das Unidades formadoras de colônias por $100 \mathrm{~mL}$ de água.

Conforme a Tabela 2, dos 43 reservatórios amostrados, 37 (86\%) apresentaram coliformes totais, sendo que 20 (46,5\%) continham bactérias Escherichia coli, variando na faixa de 6 á 1.100 UFC. $100 \mathrm{~mL}^{-1}$. $\mathrm{H}_{2} \mathrm{O}$ e 7 á 400 UFC. $100 \mathrm{~mL}^{-1}$. $\mathrm{H}_{2} \mathrm{O}$, respectivamente, apresentando-se fora dos padrões de potabilidade estabelecidos pelo Ministério da Saúde (BRASIL, 2011).

Pode ser observado em comparativo, Tabela 1 e Tabela 2, que dos 37 reservatórios contaminados, $13,51 \%$ armazenavam água proveniente de poços que não apresentaram contaminação por bactérias do grupo coliforme.

Dos poços contaminados, 21 apresentaram somente a presença de coliformes totais, sendo que, 14 reservatórios abastecidos por estes poços apresentaram também bactérias Escherichia coli. Além deste fator, foi observado, um aumento considerável no numero de coliformes totais na água dos reservatórios em relação aos poços, sendo assim, evidencia-se problemas no armazenamento e distribuição da água,

Estes resultados mostram que as más condições de captação e armazenamento da água são possíveis fontes de contaminação microbiana da água.

Outros estudos relatam a presença de bactérias do grupo coliformes em 42,8\% das águas dos poços de propriedades rurais de Jaboticabal - SP (NUNES, et. al, 2010). 
Silva e Araújo (2003), avaliando a qualidade de água de manancial subterrâneo em áreas urbanas de Feira de Santana (BA) diz que foi expressivo o percentual de amostras com coliformes totais $(90,8 \%)$ e fecais $(65,8 \%)$, variando de 2 a mais de 1.600 UFC. $100 \mathrm{~mL}^{-1}$. $\mathrm{H}_{2} \mathrm{O}$. Em Azevedo (2006), não foram detectadas presença de coliformes totais e Escherichia coli, pois a possibilidade de contaminação por esses microrganismos seria através da infiltração no poço de águas de escoamento superficial.

Cabe ressaltar que a água consumida nos assentamentos rurais de Teodoro Sampaio não passa por nenhum tipo de tratamento, requisito fundamental para garantir a manutenção da saúde e evitar a proliferação de doenças de veiculação hídrica. Esta realidade é a mesma de um número considerável de assentamentos da reforma agrária no país, que segundo o MST (2010) 45\% não tem água potável. Tão grave é a situação de abastecimento de água para consumo humano que as estatísticas da Organização Mundial de Saúde mostram que, no Brasil morrem atualmente 29 pessoas/dia por doenças decorrentes da má qualidade da água e do não tratamento de esgotos e cerca de $70 \%$ dos leitos dos hospitais são ocupados por pessoas que contraíram doenças transmitidas pela água contaminada.

\section{CONCLUSÃO}

Os resultados mostraram que $86 \%$ das famílias que ocupam os lotes nos assentamentos estudados, consomem água fora dos padrões de potabilidade preconizados pelo Ministério da Saúde. Além disso, pode ser evidenciado que a possível fonte de contaminação provém da falta de higienização dos reservatórios de água e da má construção dos poços.

\section{REFERÊNCIAS}

ANA - Agencia Nacional de Águas. Estudo de Consolidação dos Procedimentos Metodológicos na Elaboração do Relatório de Conjuntura de Recursos Hídricos / Relatório Final - RF / Estruturação da Base de Dados. Estudos realizados pela empresa TC/BR Tecnologia e Consultoria Brasileira S.A. - Brasília: SPR, 118p. 2005. 


\section{Semonem \\ Fórum Ambiental}

da Alta Paulista

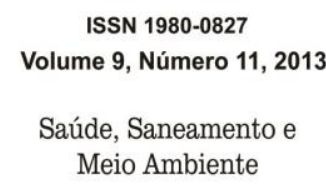

Meio Ambiente

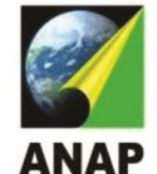

ANAP

APHA - American Public Health Association. Standard methods for examination of water and wastewater 21th ed. Washington: EPS Group, 2005.

AZEVEDO, R.P. Uso de água subterrânea em sistema de abastecimento público de comunidades na várzea da Amazônia central. Rev. Acta Amazônica, Manaus, v.36, n.3, p. 313- 320 2006. Disponível em: http://www.scielo.br/scielo.php?script=sci_ arttext\&pid=S004459672006000300004\&lng=pt\&nrm=iso. Acessado em 20 de nov. 2012.

BRASIL. Portaria no 2914 de 12 de dezembro de 2011 do Ministério da Saúde. Dispõe sobre os procedimentos de controle e de vigilância da qualidade da água para consumo humano e seu padrão de potabilidade. Diário Oficial da União, Brasília, DF, 14 dez. 2011. Disponível em: <http://portal.saude.gov.br/portal/arquivos/pdf/port_2914 _qualidade_h2o.pdf. Acesso em: 27 Abr. 2012.

BRASIL. Ministério da Saúde. Secretaria de Vigilância em Saúde. Vigilância e controle da qualidade da água para consumo humano. Brasília: Ministério da Saúde, 2006.

CASALI, A. C. Qualidade da água para consumo humano ofertada em escolas e comunidades rurais da região central do rio grande do sul.2008. 173f. Dissertação (Mestrado), Pós - Graduação em Ciência do Solo Universidade Federal de Santa Maria, Santa Maria/RS.

IBGE - Instituto Brasileiro de Geografia e Estatística. Pesquisa nacional de saneamento básico - PNSB: 2008. Rio de Janeiro: IBGE, 2010. Disponível em: http://www.ibge.gov.br/home/estatistica/populacao/condicaodevida/pnsb2008/PNSB_2008 .pdf. Acessado em: 10 de mai. de 2013.

INSTITUTO TRATA BRASIL. Perdas de água: Entraves ao avanço do saneamento básico e riscos de agravamento à escassez hídrica no Brasil. 2013. Disponível em http://www.tratabrasil.org.br/perdas-de-agua. Acessado em 06 de ago. de 2013.

MATOS, B. A. Avaliação da Ocorrência e do Transporte de Microrganismos no Aqüífero Freático do Cemitério de Vila Nova Cachoeirinha, Município de São Paulo. 2001. 172f. Tese (Doutorado). Universidade do Estado de São Paulo, Instituto de Geociências, Programa de Pós Graduação em Recursos Minerais e Hidrogeologia.

MST - Movimento dos Trabalhadores Rurais Sem Terra. Os assentamentos. publicado em nov. de 2010. Disponível em: http://www.mst.org.br/node/8606 Acessado em 06 de ago. de 2013

NUNES, et. al. Qualidade da água subterrânea e percepção dos consumidores em propriedades rurais. Rev. Nucleus. v. 7, n.2, outubro de 2010. Disponivel em: http://dialnet.unirioja.es/servlet/articulo?codigo=4039117. Acessado em 22 de set. de 2013. 
SANTONI, L. Saneamento Básico e Desigualdades: o financiamento federal da política pública (2003 - 2009). 2010. 161 f. Dissertação Mestrado (Centro de Desenvolvimento Sustentável) - Universidade de Brasília, Brasília.

SANTOS, S. M.; GOUVEIA, N. Presença de trialometanos na água e efeitos adversos na gravidez. Revista Brasileira de Epdemiologia. v. 14, n. 1, São Paulo. Março 2011. Disponível em: http://www.scielosp.org/scielo.php?pid=S1415-90X2011000100010\& script=sci_arttext. Acessado em 22 de jul. de 2013.

SILVA, R. C. A.; ARAUJO, T. M. Qualidade da água do manancial subterrâneo em áreasurbanas de Feira de Santana (BA). Rev.Ciência \& Saúde Coletiva, São Paulo, v.8 n.4, p.1019- 1028, 2003. Disponível em: www.scielo.br/pdf/csc/v8n4/a23v8n4.pdf Acessado em: 1 de nov. de 2012.

TEODORO SAMPAIO. (Município). Plano Municipal de Desenvolvimento Rural Sustentável (2010 - 2013). Teodoro Sampaio, 18 de junho de 2010.

VALENCIANO, R.C. Processo de luta pela terra e seus desdodabrementos no município de Teodoro Sampaio, Revista Pegada v. 2, n. 1, 2001. Disponível em: http://revista.fct.unesp.br/index.php/pegada/article/view/778. Acessado em 06 mai. 2013. 